\title{
Supercapacitance Performances of Electrodeposited Nickel Oxide/Graphene Nanocomposite
}

\author{
Chunxiao Yin ${ }^{1,2}$, Wencheng Wan ${ }^{1,3}$, Hui Xie ${ }^{1}$, Wenju Weng ${ }^{2}$, Guangjiu Li ${ }^{2}$, Binghang Li ${ }^{1}$, \\ Yubao Wang ${ }^{1}$, Xianqun $\mathrm{Wu}^{1}$, Wei Sun ${ }^{1, *}$ \\ ${ }^{1}$ Key Laboratory of Laser Technology and Optoelectronic Functional Materials of Hainan Province, \\ College of Chemistry and Chemical Engineering, Hainan Normal University, Haikou 571158, P R \\ China \\ ${ }^{2}$ College of Chemistry and Molecular Engineering, Qingdao University of Science and Technology, \\ Qingdao 266042, P R China \\ ${ }^{3}$ Key Laboratory of Marine Environmental Corrosion and Bio-fouling, Institute of Oceanology, \\ Chinese Academy of Sciences, Qingdao 266071, China \\ *E-mail: sunwei@qust.edu.cn
}

doi: $10.20964 / 2019.05 .53$

Received: 10 October 2018 / Accepted: 5 March 2019 / Published: 10 April 2019

In this paper graphene (GR) was obtained by electrochemical reduction of graphene oxide on the surface of nickel foam (NF). Then $\mathrm{NiO}$ nanocrystals were obtained on the GR/NF surface by electrochemical method to get $\mathrm{NiO} / \mathrm{GR} / \mathrm{NF}$ electrode, which was characterized by scanning electron microscopy (SEM). Various electrochemical methods such as cyclic voltammetry, AC impedance, constant current charge and discharge were used to test the electrochemical performances of the electrode. The results indicated that the capacitive properties of the composite were improved effectively due to the presence of nanometer-sized $\mathrm{NiO}$ and GR, and the specific capacitance of the composite was calculated as $381 \mathrm{mF} / \mathrm{cm}^{2}$ at current density of $1 \mathrm{~mA} / \mathrm{cm}^{2}$. The specific capacitance retention rate of 1000 cycles at high current density was $97.4 \%$ with good cycle stability, which indicated that $\mathrm{NiO} / \mathrm{GR}$ composite could be used as good supercapacitor material.

Keywords: Nickel oxide, Graphene, Nanocomposite, Supercapacitors, Electrochemistry.

\section{$\underline{\text { FULL TEXT }}$}

(C) 2019 The Authors. Published by ESG (www.electrochemsci.org). This article is an open access article distributed under the terms and conditions of the Creative Commons Attribution license (http://creativecommons.org/licenses/by/4.0/). 